phosphates and their thio derivatives in urine is established for the OPP biomonitoring. However, this approach does not provide information on the exposure to specific OPP agents. A lot of OPP as well as some carbamates also provide specific urinary biomarkers indeed. For a specific biomonitoring approach we developed an analytical procedure, which enables the assessment of a wide spectrum of phenolic metabolites of OPP and carbamates in human urine.

Methods After enzymatic cleavage of possible glucuronide and sulfate conjugates, the analytes were extracted by solid phase cartridges and derivatized with $\mathrm{N}$-methyl-N-(trimethylsilyl)-trifluoroacetamide. The prepared samples were determined by GC-MS/MS using electron impact ionisation and multiple reaction monitoring mode. The validated method was applied to samples derived from occupational and environmental exposure.

Results The procedure enables the simultaneous quantification of 9 biomarkers for OPP exposure (4-tert-butyl-2-chlorophenol, 3-chloro-7-hydroxy-4-methylcoumarin, 2-(diethylamino)6-methylpyrimidin-4-ol, 2-isopropoxy-6-methylpyrimidin-4-ol, 3-methyl-4-(methylthio)phenol, 3-methyl-4-nitrophenol, 4(methylthio)phenol, 4-nitrophenol, 3,5,6-trichloro-2-pyridinol) and 7 biomarkers for carbamate exposure (2-amino-5,6-dimethylpyrimidin-4-ol, 2-(dimethylamino)-5,6-dimethyl-pyrimidin4-ol, 2,2-dimethylbenzo[1,3]dioxol-4-ol, 2,2-dimethyl-2,3-dihydrobenzofuran-7-ol, 3,5-dimethyl-4-(methylthio)phenol, 2-isopropoxyphenol, 1-naphthol).The method showed detection limits between 0.1 and $0.3 \mu \mathrm{g} / \mathrm{L}$. Variation coefficients ranged from $2 \%$ to $10 \%$ for precision in series and $2 \%$ to $14 \%$ for inter-day precision. Furthermore, recovery rates between $87 \%$ and $120 \%$ were determined.

Discussion The method showed high reliability and robustness. It enables the simultaneous and specific monitoring of a wide spectrum of pesticides and biocides whose structures contain aryl moieties. The multicomponent procedure can be used for biomonitoring of agriculture workers, bystanders and general populations.

\section{URINARY TRIMETHYLTIN REFLECTS BLOOD TRIMETHYLTIN IN SCRAP RECYCLING WORKERS}

${ }^{1} \mathrm{G}$ Ichihara*, M lida, T Fujie, T Kaji, ${ }^{2} Y$ Kim. ${ }^{1}$ Tokyo University of Science, Noda, Japan; ${ }^{2}$ University of Ulsan College of Medicine, Ulsan, Korea

\subsection{6/oemed-2018-ICOHabstracts. 1156}

Introduction We recently reported cases of scrap recycling workers intoxicated with organotin, who showed severe encephalopathy with symptoms of memory disturbance. The study showed higher ratio of urinary trimethyltin to urinary dimethyltin in the workers than that in the previous cases exposed to only dimethyltin, suggesting co-exposure to dimethyltin and trimethyltin in the present cases. The present study subsequently investigated blood dimethyltin and trimethyltin to understand the relationship of urinary and blood dimethlytin/ trimethyltin for evaluation of validity of them as exposure markers for organotin.

Methods Urinary and blood dimethyltin and trimethyltin at different time points in three workers were measured with HPLC-ICP/MS. Regression analyses were conducted with independent values of blood dimethyltin and trimethyltin and dependent values of urinary dimethyltin and trimethyltin respectively. Multiple regression analysis with dummy variable of individual was also conducted for adjustment of individual factors.

Result Regression analysis showed significantly positive relation of urinary trimethyltin to blood trimethyltin, but did not show significant relation of urinary dimethyltin to blood dimethyltin. Multiple regression analysis with individual factor also showed significantly positive relation of urinary trimethyltin to blood dimethyltin.

Discussion The study shows that urinary trimethyltin reflects blood trimethyltin. In co-exposure to trimethytin and dimethyltin, urinary trimethyltin can be an internal exposure marker of trimethyltin, which is considered to be not only derived from external exposure to trimethyltin but also the trimethyl tin converted from dimethyltin, in human body.

\section{HUMAN BIOMONITORING FOR EXPOSURE ASSESSMENT OF BENZENE DURING SHORT-TERM MAINTENANCE WORK}

T Jäger*, S Bäcker, C Oberlinner, M Bader. BASF SE, Corporate Health Management, Ludwigshafen, Germany

\subsection{6/oemed-2018-ICOHabstracts. 1157}

Introduction Human biomonitoring (HBM) is frequently used for exposure analysis and assessment of maintenance workers potentially exposed to benzene during turnaround works. In Germany, the Technical Rule for Hazardous Substances (TRGS) 910 provides three biomarkers for benzene: S-phenylmercapturic acid (SPMA), trans, trans-muconic acid (ttMA) and unmetabolized benzene in urine. The aim of the present HBM study was to compare the validity and applicability of the different biomarkers for exposure assessment during a turnaround.

Methods In 2016, 143 post-shift urine samples of 119 maintenance workers with potential exposure to benzene were analysed. In each sample urinary benzene, SPMA and ttMA were measured according to procedures recommended by the German Research Foundation (DFG). The biomonitoring equivalents of the tolerance concentration according to the TRGS 910 were used as internal action values: $0.5 \mathrm{mg}$ ttMA/g creatinine, $25 \mu \mathrm{g} \mathrm{SPMA} / \mathrm{g}$ creatinine, $5 \mu \mathrm{g}$ benzene/L urine.

Results The median values were $0.09 \mathrm{mg} / \mathrm{g}$ creatinine (range: $<$ LOQ - $1.76 \mathrm{mg} / \mathrm{g}$ creatinine) for ttMA, <LOQ (range: $<\mathrm{LOQ}-73.5 \mu \mathrm{g} / \mathrm{g}$ creatinine) for SPMA and $0.5 \mu \mathrm{g} / \mathrm{L}$ (range: $0.1-9.9 \mu \mathrm{g} / \mathrm{L}$ ) for urinary benzene. Action value excursions were observed in less than $2 \%$ of the post-shift samples for SPMA, 4\% for ttMA and 7\% for urinary benzene, respectively. However, the results showed that the action value excursions were not necessarily observed in the same samples, probably resulting from, e.g., peak exposures and different elimination half-lives.

Conclusion The HBM program has shown a low overall occupational exposure to benzene during turnaround works. With respect to applicability and validity, urinary SPMA is the biomarker of choice for the reliable HBM of benzene exposures. ttMA has a critically low diagnostic sensitivity, while unmetabolized urinary benzene demands special attention to avoid external contamination. Nevertheless, urinary benzene allows for a rapid and relatively cost-efficient analysis and it is well suitable for screening purposes. 